\title{
El anARChivismo en Walter BenJamin. Sobre la PRÁCtica del COLECCIONISTA Y LA FILOSOFÍA MATERIALISTA DE LA HISTORIA
}

\author{
[THE ANARCHIVISM IN WALTER BENJAMIN. ON THE PRACTICE OF THE COLLECTOR AND THE \\ HISTORICAL MATERIALISM]
}

Andrés Maximiliano Tello *

\begin{abstract}
RESUMEN: El objetivo de este artículo es ahondar en la reflexión filosófica de Walter Benjamin sobre el coleccionismo, detallando al mismo tiempo su íntimo vínculo con la particular noción de materialismo histórico desarrollada por el autor del Passagen-Werk. Tomando como base el análisis de los diversos textos y documentos en los que Benjamin se refirió al problema del coleccionismo, escritos principalmente entre 1928 y 1940 , postulamos que una manera posible de entender la conexión entre la práctica del coleccionista y el materialismo histórico, es mediante lo que hemos denominado aquí anarchivismo. Con dicho término, nos referimos básicamente a la alteración radical del orden y las clasificaciones institucionales que conforman los archivos históricos y culturales. Nuestra tesis finalmente apunta a que la noción de anarchivismo permite comprender no sólo la reflexión filosófica de Benjamin sobre el coleccionismo y el materialismo histórico, sino que también la manera en que su propio pensamiento los pone en práctica.
\end{abstract}

Palabras Clave: Anarchivismo, Benjamin, coleccionismo, materialismo histórico.
ABSTRACT: The aim of this article is to delve into the philosophical reflection of Walter Benjamin on collecting, explaining in detail its intimate bond with the particular notion of historical materialism developed by the author of the Passagen-Werk at the same time. Based on the analysis of various texts and documents in which Benjamin referred to the problem of collecting, written mainly between 1928 and 1940, we stated that a possible way to understand the connection between the practice of collector and historical materialism, is through what we name here anarchivism. With this term, we refer primarily to the radical alteration of the order and institutional classifications that make up the historical and cultural archives. Our thesis finally suggests that the notion of anarchivism makes possible understanding not only Benjamin's philosophical reflection on collecting and historical materialism, but also how his own thought puts them into practice.

KEYWORDS: Anarchivism, Benjamin, collecting, historical materialism.

G $\mathrm{n}$ uno de los aforismos de su texto de 1928, Einbahnstrasse [Calle de dirección única], Walter Benjamin (2010a, p. 42) hace un curioso diagnóstico: las recientes transformaciones tecnológicas ligadas a la escritura parecen indicar que el libro "está llegando ya a su fin en la forma hoy tradicional". Según el filósofo, la escritura comenzaba a exceder sus antiguos soportes, y el surgimiento de nuevos modos de producción del conocimiento convierte entonces al libro en una mediación anticuada entre diferentes "sistemas de ficheros" [Kartothekssystemen], a tal

* Doctor en Filosofía, académico del Departamento de Sociología de la Universidad de PlayaAncha,Chile.m@ilto: andresmaximilianotello@gmail.com 
punto que ahora "todo lo esencial se encuentra guardado en el fichero [Zettelkasten] del investigador que escribió el libro, y el erudito que lo estudia lo va asimilando a su propio fichero [Kartothek]» (Benjamin, 2010a, p.43). De esta observación, por cierto, se desprende que ya no habría una posibilidad de generar conocimiento sin entrar en cierta relación con el archivo, con sus diversas técnicas o registros. Pero se insinúa aquí también el particular vínculo que el propio Benjamin tiene con el archivo, que marca tanto su biografía como una significativa dimensión de su pensamiento filosófico.

Podría afirmarse que, durante los últimos treinta años de su vida, Benjamin no deja de preocuparse constantemente de idear una obra y de ir archivándola con prolijidad, por ejemplo, distribuyendo de modo estratégico copias de sus trabajos entre sus amigos más cercanos. De ese manera, los documentos que en su momento él le envía a Alfred Cohn y Gershom Scholem, finalmente "sirvieron de depósitos de su pensamiento y de su escritura" (Marx, 2010, p. 25).

No cabe duda de que el filósofo alemán resguarda con un rigor casi de archivista todos sus textos y elementos de trabajo. Como bien lo índica Esther Leslie (2007, p. 9), él conserva: "carpetas, sobres, cajas y estuches que albergaban correspondencia, (...) memorias, diarios, fotografías, postales, dibujos y notas, fichas, inventarios, una lista de libros leídos desde sus días escolares y una lista de sus publicaciones, así como copias de sus escritos y varios borradores". Sin embargo, un contrapunto de esta aparente meticulosidad en la disposición de su archivo personal puede encontrarse en la misma forma en que Benjamin produce esos materiales, marcada por una práctica de escritura impulsiva y desorganizada. Se trata de una curiosa tendencia a la dispersión pues, de acuerdo con Pierre Missac (1997, p. 72), "las notas generales, observaciones personales o citas las anota en lo que tenga a su alcance, cualquier cosa, páginas arrancadas de un block publicitario, comprobantes bancarios," etc. De este modo, la innegable preocupación de Benjamin por conservar sus archivos parece tensionada por el gesto incontrolable con el que él mismo elabora sus documentos.

Es a propósito de esta paradoja que Erdmut Wizisla (2010a, p. 18) ha subrayado un importante punto: «Orden, eficiencia, integridad y objetividad son los principios del trabajo de archivo. Por el contrario, los archivos de Benjamin revelan la pasión del coleccionista». Mientras el archivo responde a estrictos criterios organizativos, en cambio, los impulsos del coleccionista resultan difíciles de encuadrar. Al no reflejar los tradicionales criterios objetivos y racionales que persigue la archivística en la conformación de sus depósitos, los documentos de Benjamin parecen entregados a un principio más bien caótico, donde la ordenación y clasificación de los contenidos "parece falseada, marcada por recuerdos y sentidos subjetivos" (Marx, 2010, p. 26). Por lo tanto, en contraposición al orden reclamado por los archivos históricos y culturales de nuestra civilización, estos legajos serían más bien la expresión de lo que proponemos llamar un anarchivismo, es decir, un movimiento que altera los sistemas normalizados de organización del mundo sensible y sus registros. De acuerdo con lo anterior, a continuación revisaremos cómo esta noción de anarchivismo puede ser comprendida de la mano con la práctica del coleccionismo teorizada y experimentada por Benjamin, hasta el punto de convertirse en una posible clave para la lectura de su "filosofía materialista de la historia" (Buck-Morss, 1995, p. 19).

\section{PASión y desorden}

La faceta de Walter Benjamin como coleccionista -ya sea de libros, pequeños objetos o imágenes-, es frecuentemente reconocida por sus biógrafos (Leslie, 2007; Tackels, 2012). Desde niño mantuvo una colección de postales, herencia de los viajes de su abuela materna, que él ampliaría más tarde con las tarjetas recolectadas en sus propias travesías por Europa. Esta temprana relación con el coleccionismo no es casual, pues para Benjamin (2010a, p. 55), se trata de una característica distintiva de la 
infancia, tal cual como lo señala en su descripción del "niño desordenado":

Cada piedra que encuentra, cada flor que recoge, cada mariposa que atrapa es el comienzo de una colección, y ello a pesar de que todas sus propiedades forman para él una sola. Esa pasión nos muestra en él su rostro, esa mirada india tan severa que en anticuarios, investigadores y bibliómanos ya sólo arde sin lustre. En cuanto empieza a vivir, el niño se convierte en un gran cazador. Caza los espíritus, cuya huella rastrea entre las cosas (...).

El acto de coleccionar entraña pues una verdadera pasión, que se observa ya en la infancia y que no desaparece luego en los grandes coleccionistas y estudiosos. Sin embargo, la práctica del coleccionismo excede el ámbito meramente biográfico de Benjamin, pues no puede aislarse de la elaboración de su propio pensamiento filosófico. Este vínculo queda muy claro en una carta que Benjamin escribe en 1940, poco antes de morir, a la poeta y librera Adrianne Monnier, donde comenta la nostalgia que aún siente por el abandono de su biblioteca, al escapar de Alemania en 1933. Benjamin -citado por Allen (2000, p.12)-, confiesa entonces que "las pasiones que, en otro tiempo, se dirigían a las piezas que me obsesionaban han girado hacia una búsqueda abstracta, hacia la esencia de la colección en sí misma". Más que un simple gesto retórico para expresar la añoranza por los objetos perdidos, lo que se pone de manifiesto aquí es una verdadera preocupación filosófica por la práctica del coleccionismo. Una inquietud que no es nueva ni marginal en el pensamiento benjaminiano.

Casi diez años antes de la citada carta, en 1931, Benjamin publica un breve ensayo sobre el mismo tema: Ich packe meine Bibliothek aus. Eine Rede über das Sammeln [Voy a desembalar mi biblioteca. Un discurso sobre el coleccionismo]. El texto se propone ahondar en "la relación de un coleccionista con sus posesiones", y al mismo tiempo, comprender "el arte de coleccionar" (Benjamin, 2010c, p. 337). Por ello, comienza relatando una escena donde desempaca su propia colección de libros, en medio de las cajas abiertas y pilas de ejemplares, para postular inmediatamente que: "la vida del coleccionista evoluciona en tensión dialéctica entre los polos del orden y del desorden" (ibid.). Podría decirse que la figura del «orden» remite aquí, en primera instancia, a la simetría de los estantes, es decir, a la organización característica de las bibliotecas, que implica de algún modo una disposición institucional. En efecto, tal como lo sugiere ya la palabra griega bibliotheke, el lugar de depósito de los libros, remite al "acto de colocar, volver a poner, pero también inmovilizar, confiar a la inmovilidad estabilizadora y, por lo tanto, al estatus, a la institución estatutaria, incluso estatal", esto es, a ciertas "dimensiones institucionales, jurídicas y políticas" (Derrida, 2003, p. 17). Así, la agrupación regularizada y fija de los libros no deja de sugerir un orden instituido.

Desde luego, en su discurso sobre el coleccionismo, Benjamin no busca establecer una norma estándar para el sitio de los libros en los armarios, ni determinar el modelo perfecto de una colección: “¿No sería presuntuoso el recurrir aquí a una aparente objetividad para ir enumerando las secciones que componen una biblioteca o la historia de su formación, o incluso explicarles su utilidad para el escritor?" (Benjamin, 2010c, p. 337). El motivo de esta renuncia a sugerir criterios o formas de organización de una biblioteca radica en que la práctica del coleccionismo "no tiene como fundamento la «exactitud», la «catalogación del material» o el «inventario completo de todos los datos»" (Wizisla, 2010a, p. 21), pues esos elementos se enmarcan más bien dentro de las operaciones de jerarquización, clasificación, valorización y control institucional de las colecciones. En otras palabras, si el discurso sobre el coleccionismo de Benjamin rechaza el establecimiento de principios objetivos de clasificación es porque estos son el fundamentos de una colección mantenida por el archivo institucional, no el de la práctica del coleccionista y su arte. Este último no puede evitar tensionar el orden con un polo de desorden, desde el cual se impulsa además su propia relación pasional con los objetos coleccionados.

"Toda pasión confina con el caos; y la pasión de coleccionar, con el caos donde yacen los recuerdos" (Benjamin, 2010c, p. 337). Esto se aprecia en la escena ya 
mencionada del desembalaje de los libros, pues aunque el filósofo se preocupe de inspeccionar rigurosamente el contenido de las cajas abiertas, comprobando las existencias con el catálogo de sus libros, al mismo tiempo, las evocaciones que cada ejemplar puede gatillar en él, provocan una diseminación incontenible de recuerdos. El orden del almanaque estalla así en el desorden singular de la relación entre el coleccionista y los objetos que componen su colección. Estos últimos adquieren su valor, en buena parte, en la rememoración que son capaces de provocar. Es por esta razón que, a diferencia del ordenamiento del archivo, el "arte de coleccionar" es impulsado principalmente por la pasión del coleccionista y el singular devenir de sus recuerdos. En ese sentido, para Benjamin, existe un íntimo vínculo que se teje entre la irrupción de la memoria y la práctica del coleccionista. De hecho, en un breve texto que jamás publicó en vida, Benjamin compara el acto de recordar con una ferviente excavación del pasado, en la que no sólo se vuelve una y otra vez a la situación pretérita, sino que además las imágenes evocadas, "arrancadas de todos sus contextos anteriores, aparecen como objetos de valor en los aposentos sobrios de nuestra comprensión tardía, como torsos en la galería del coleccionista" (Benjamin, 2010b, p. 350). Los encuentros repentinos de la memoria con las inscripciones del pasado, de la experiencia vivida, son así comparados con los hallazgos del coleccionista, que ha escarbado también entre los objetos de la historia cultural.

Antes que homologar el arte de coleccionar a los procedimientos del archivo, es decir, de la organización institucional de las colecciones, la filosofía benjaminiana nos lleva más bien a diferenciarlos radicalmente, en tanto asume que el primero despliega el proceso transformador de la memoria involuntaria, alterando así los principios de ordenamiento del segundo, esto es, del archivo como memoria voluntariamente registrada y organizada. Esta noción de memoria involuntaria, que Benjamin recoge de Proust, demuestra que la experiencia del recuerdo es siempre azarosa y, sobre todo, nos enfrenta al "transcurso del tiempo en su figura real", es decir, a la emergencia del "tiempo entrecruzado". Y es justamente allí donde asoma la experiencia de la memoria como acontecimiento irreductible (Benjamin, 2007a, p. 318). Lo anterior es subrayado por Benjamin en el legajo $\mathrm{H}$ del Passagen-Werk, dedicado justamente a la figura del coleccionista, y donde se afirma que una "especie de desorden productivo es el canon de la memoria involuntaria, y también del coleccionista. (...) La memoria voluntaria, por el contrario, es un registro que dota al objeto de un número de orden bajo el que éste desaparece" (Benjamin, 2005, p. 229).

En medio del archivo, el potencial desorden de la figura del coleccionista suspende así los principios que buscan instituir un ordenamiento objetivo de las cosas y los signos, abriéndose el paso entre la uniformidad administrativa, franqueando sus límites. Por eso, según Benjamin (2010c, p. 338), para el coleccionista "todo orden es como estar colgado ante un abismo". Esto quiere decir, por supuesto, que no hay síntesis posible entre el polo del ordenamiento del archivo y la pasión del coleccionista que se abre al caos, pues la fuerzas que contraponen ambos polos ocasionan en realidad la suspensión del sometimiento definitivo de cualquiera de ellos. Dicho de otro modo, el coleccionista no puede sino relacionarse con sus cosas, con las piezas de la colección, a partir del desorden que le evocan, desde una multiplicidad de conexiones donde cualquier orden resulta inestable. Frente a los estándares archivísticos tradicionales, la singular pasión del coleccionista se muestra insumisa, imposible de ajustar a criterios generales de clasificación.

La pasión del coleccionista se mueve entonces en el archivo revocando los principios mismos de la archivística, es decir, su práctica despliega inevitablemente un anarchivismo en los registros institucionalizados de la memoria o de la historia cultural. Y si bien es innegable que las piezas de cualquier colección pueden ser vistas desde cierto orden momentáneo, esto no implica que el anarchivismo inmanente al arte de coleccionar se diluya, pues la organización dispuesta por el coleccionista debe entenderse siempre de una manera muy particular: de un modo "que posibilita variantes, reordenaciones, heteronomías, una organización que genera significados y 
desintegra lecturas" (Hernández, 2002, p. 167). En ese sentido, el anarchivismo no es incompatible con el arte de coleccionar, pues el desorden del coleccionista es siempre un desorden creativo. Lejos de abogar por clasificaciones rígidas o el establecimiento de las procedencias inalterables, la pasión del coleccionista se manifiesta así en la suspensión de cualquier síntesis de la dialéctica entre archivo y colección.

\section{El anarchivo del Passagen-Werk}

En una de las nota del legajo H, de su Passagen-Werk, Benjamin sostiene que el "coleccionismo es un fenómeno originario del estudio: el estudiante colecciona saber" (2005, p. 228). Esta tesis se confirma precisamente en el mismo e inconcluso proyecto benjaminiano, compuesto a partir de una gran colección citas. De acuerdo con Adorno (1995, p. 22), el ambicioso proyecto del Libro de los pasajes tenía como objetivo compendiar los rasgos primordiales del siglo XIX y, a partir de ellos, "construir la idea de la época, en el sentido de una prehistoria de la modernidad". Si bien las abundantes citas recopiladas por Benjamin con rigurosidad y esmero durante las diferentes etapas de este trabajo - desarrolladas entre 1926 y 1940-, buscaban trazar la historia material del siglo XIX, lo cierto es que el conjunto de sus legajos no pueden ser estrictamente definidos como un archivo. Los motivos de esta incompatibilidad, de este desajuste, entre la colección bejaminiana de citas que componen el inconcluso Libro de los pasajes y cualquier otro archivo histórico o cultural, son diversos, pero podríamos mencionar al menos dos que resultan importantes aquí.

Para empezar, esta colección singular no se limita a reconstruir un siglo anterior o un simple archivo histórico precedente del siglo XX. Y esto porque la tarea que la cita juega aquí no es trivial: para Benjamin (2005, p. 478), la cita no conserva ningún marco de procedencia, al contrario, se forja en la destrucción de cualquier recuadro que pudiera contenerla, pues "en el concepto de citación radica que el correspondiente objeto histórico sea arrancado de su contexto". De acuerdo con esta premisa benjaminiana, podría sostenerse que la colección que compone el Libro de los pasajes no pretende instaurar un archivo histórico o restaurar el pasado como una totalidad, sino que en el gesto de Benjamin la inscripción de la historia deviene su cita, destruyendo así los marcos de lectura tradicionales.

De ahí que, en segundo lugar, la multiplicidad de imágenes, firmas, datas, acontecimientos, estilos y detalles disparados en cada cita que compone el Libro de los Pasajes, no termina sometida a un ordenamiento orgánico. Al contrario, como bien lo indica Wizisla (2010b, p. 43):

Benjamin trataba frecuentemente los elementos de sus textos conforme al principio de las unidades de montaje; los copiaba, los recortaba, los pegaba en nuevas hojas y los rehacía, mucho antes de que este procedimiento se estableciera con la expresión copy and paste en el procesamiento electrónico de textos (...). La idea de Benjamin de escribir un trabajo enteramente con citas supone la posibilidad de movilizar el material dentro de la colección, de poder cambiar de sitio elementos a voluntad. Al principio, todo tiene la misma categoría; el saber que debe organizar la ficha no conoce de ninguna jerarquía.

La colección de Benjamin opera desplazando cualquier referente unívoco y las lecturas cerradas de los elementos que la componen, y al mismo tiempo, genera conocimiento a través las citas reunidas y de su montaje. No hay pues en estos ficheros contenidos que sean inamovibles, ni jerarquizables a priori. De esa manera, la cita compone y descompone distintos contextos históricos a partir del uso particular que hace de las imágenes y referencias pretéritas. Puesto de otro modo, la fuerza de la cita permite un rescate de lo pretérito que no opera tanto por la conservación sino mediante un gesto destructivo que arranca lo ya sido del curso ordenado del tiempo. Potencia de la cita que "es la única que infunde todavía la esperanza de que algunas cosas sobrevivan a este escaso espacio temporal, precisamente porque las han sacado de él" 
(Benjamin, 2007b, p. 374). Así ocurre también con los contenidos que la cita arranca de los archivos: el procedimiento de la cita no se ajusta a una subordinación orgánica o rígida, que es característica de la constitución del archivo. El coleccionista de citas desajusta entonces el código fijo de referencia en los ficheros, en un gesto que desafía también toda procedencia restituible a algún depósito.

Cada legajo [konvolut] de citas que Benjamin colecciona es ensamblado en una organización heteróclita. Treinta y seis konvoluts componen el Libro de los Pasajes, cuyos títulos dejan entrever la pluralidad de sus materiales: Pasajes, tiendas de novedades, vendedores; Moda; París antiguo, Catacumbas, Demoliciones, Ruinas de París; Aburrimiento, Eterno retorno; Haussmanización, Lucha de barricadas; Construcción en Hierro; Métodos de exhibición, Publicidad, Grandville; El Coleccionista; El interior, Huella; Baudelaire; Ciudad de sueños y casa de sueños, Sueños del futuro, Nihilismo antropológico, Jung; Casa de sueños, Museo, Fuente; El Flâneur; Epistemología, Teoría del Progreso; Prostitución, Apuestas; Las calles de París; Panorama; Espejo; Pintura, Jugendstil, Novedad; Formas de iluminación; SaintSimon, Ferrocarriles; Conspiraciones, Compagnonnage; Fourier; Marx; Fotografía; Muñeco, autómata; Movimiento social; Daumier; Historia literaria, Hugo; Bolsa, Historia económica; Tecnologías de reproducción, Litografía; La Comuna; El Sena, el París más antiguo; Ocio; Materialismo antropológico, Historia de las sectas; y Ecole Polytechnique $^{1}$. Esta es la manera general en que Benjamin dispone la mayor parte de las citas recolectadas a lo largo de casi quince años. El índice de esta colección es incompatible con un modelo general o con cualquier esquema asimilable a los criterios de orden que rigen todo archivo. Por lo tanto, los legajos de Benjamin convulsionan su propio archivo, pues cualquier plan de inventario de los fragmentos que se dan cita aquí acaba estremecido. Y esto porque, en último término, su conexión en legajos nunca tuvo otro propósito más que el de la recuperación crítica de una práctica del montaje: "levantar las grandes construcciones con los elementos constructivos más pequeños, confeccionados con un perfil neto y cortante. Descubrir entonces en el análisis del pequeño momento singular, el cristal del acontecer total" (Benjamin, 2005, p. 463). Tal disposición de lo recolectado, al mismo tiempo, pone de manifiesto también la práctica singular y el arte del coleccionista de citas.

De esa manera, el mismo proyecto del Passagen-Werk, en su composición y montaje, demuestra que existe una tensión irreductible entre la colección, o mejor dicho, entre la práctica del coleccionista que describe la filosofía benjaminiana y el funcionamiento del archivo institucional, al menos tal cual lo entiende tradicionalmente la disciplina archivística. Esta última se guía según las instrucciones decimonónicas del principio de procedencia y del principio de respeto de orden del original ${ }^{2}$. El respeto por la estructura original de los archivos apunta a la preservación del orden en que los documentos fueron dispuestos mientras dichas labores de administración se mantuvieron en funcionamiento, y es en base al supuesto criterio de objetividad que así se consigue lograr que la archivística se puede autodefinir como ciencia en el siglo XIX. Lo que implica, por un lado, que cada archivo debe ser considerado según su organización particular, o constitución orgánica, a la hora de proceder a una clasificación sistemática de sus fondos. Frente a estos criterios de organización, la colección de citas del Libro de los pasajes, con sus desplazamientos y elementos heteróclitos, se presenta más bien como un anarchivo.

\section{COLECCIONAR: TRANSFIGURAR LAS COSAS DEL MUNDO}

El anarchivismo del coleccionista no sólo trastorna las disposiciones orgánicas y jerárquicas del archivo, de su orden institucional, sino que además dispone una nueva forma de entender los objetos o las huellas que reúne en su colección. Como bien lo destaca Eckhardt Köhn (2014, p. 200), el coleccionista benjaminiano "reúne cosas de cuyo valor se encuentra convencido únicamente porque confía en su facultad estética y 
en su competencia erudita". De ahí que Benjamin no entienda el coleccionismo como un mero pasatiempo, lo concibe como un verdadero arte, o incluso como una forma de investigación, si pensamos en la misma colección de citas que combina el proyecto del Passagen-Werk. Lo fundamental aquí es que, con su arte, el coleccionista no sólo perturba el archivo cultural (las bibliotecas, museos y depósitos documentales), sino que recompone el mundo sensible y la manera de comprenderlo. Esto, por cierto, bajo una apariencia caótica, similar a la de los primeros coleccionistas de gabinetes de curiosidades o Wunderkammer, que buscaban nada menos que "reconstruir el universo en una sola habitación, en el ambiente de una colección, sobre una larga serie de recolecciones no especializadas" (Lugli, 1983, p. 11).

No debe resultar extraño entonces que la filosofía benjaminiana atribuya al arte de coleccionar una particular forma de conocimiento: "los coleccionistas son fisonomistas del extenso mundo de las cosas- se vuelven adivinos del destino" (Benjamin, 2010d, p. 338). Con ello, el coleccionista pone en cuestión las directrices del archivo que imponen en distintos momentos una definición y clasificación general del conocimiento. El arte de coleccionar no se rige por el orden de los sistemas de clasificación imperantes para organizar las piezas de su colección, sino más bien por un secreto índice. En palabras de Benjamin (2005, p. 225):

para el coleccionista el mundo está presente, y ciertamente ordenado, en cada uno de sus objetos. Pero está ordenado según un criterio sorprendente, incomprensible sin duda para el profano. Se sitúa respecto de la ordenación corriente de las cosas y de su esquematización, más o menos como el orden de las cosas en una enciclopedia, respecto de un orden natural. Basta con recordar la importancia que para todo coleccionista tiene no sólo el objeto, sino también todo su pasado, al que pertenecen en la misma medida tanto su origen y calificación objetiva, como los detalles de su historia aparentemente externa: su anterior propietario, su precio de adquisición, su valor, etc. Todo ello, los datos «objetivos» tanto como esos otros, forman para el verdadero coleccionista, en cada uno de sus ejemplares poseídos, una completa enciclopedia mágica, un orden del mundo, cuyo esbozo es el destino de su objeto.

El talante "mágico" de la organización de los elementos de la colección se debe a que su poseedor ve en ellos la múltiple conjunción de temporalidades y correspondencias que pueden articularlos. Las cosas se presentan ante el coleccionista como las estrellas que forman una constelación, mediante la cual puede leer de otro modo el porvenir del mundo. Por lo tanto, el coleccionista benjaminiano forma su propia "enciclopedia mágica" a partir de los elementos que reúne en sus prácticas anarchivistas. El arte de la colección se manifiesta así en un irreductible agrupamiento de signos y cosas: "el racional orden burgués de lo conocido y lo cognoscible como forma; la mágica y tenaz resistencia de las cosas en el lenguaje -su «nocomunicabilidad»- como contenido" (Lewandowski, 1999, p. 153). Esta particular tensión de orden y desorden en la práctica del coleccionista dificulta justamente su reacomodamiento en los casilleros del archivo. Esto quiere decir que la organización "mágica" de las piezas de una colección ocurre siempre de una manera que es completamente nueva e inderivable, ya que "la «rememoración» es el esquema de la transformación de la mercancía en objeto del coleccionista. Las correspondances [entre sus distintas piezas] son por lo tanto las resonancias infinitamente múltiples de toda rememoración de cualquier otro" (Benjamin, 2008, p. 300). Puesto en otros términos, la irreductibilidad del valor afectivo que el coleccionista otorga a los elementos de su colección, así como las conexiones heterogéneas que establece entre estos, responden al proceso transformador y singular del recuerdo que palpita en la pasión del coleccionista.

Lo anterior concuerda plenamente con la operación que el coleccionista benjaminiano lleva a cabo con las piezas que recopila, pues estas no sólo son reubicadas en el espacio particular de la colección sino que además, mediante este mismo acto, son transfiguradas. Cuestión que Benjamin $(2005$, p. 223) subraya cuando afirma que, al 
coleccionar, "lo decisivo es que el objeto sea liberado de todas sus funciones originales para entrar en la más íntima relación pensable con sus semejantes. Esta relación es diametralmente opuesta a la utilidad". Todo producto cultural muta, de algún modo, al insertarse en una colección, pues para el coleccionista el provecho de las cosas y los signos no reside en el carácter instrumental u ordinario que puedan tener, sino en la interacción particular y hasta enmarañada que cumplen con el resto de la piezas de su colección. Por lo tanto, según la filosofía benjaminiana, la práctica del coleccionista transforma los signos o los objetos que recoge en el mundo que lo rodea, pues los arranca de su marco habitual, al igual como el procedimiento de la cita, destruye los contextos de los que provienen y aquellos que interrumpen. Sin duda, esas transfiguraciones responden al hecho de que el coleccionista lleva a cabo su labor "para representarse los objetos no en el espacio de éstos, sino en el suyo propio" (Scholz, 2003, p. 6). La imagen de los gabinetes de curiosidades de la modernidad temprana, muestra de algún modo esta singularidad de la colección, puesto que en su espacio las cosas ingresan en un insólito juego de interrelaciones dispuesto exclusivamente por su poseedor. Sin embargo, la figura del coleccionista que interesa a Benjamin, y donde el fenómeno de transfiguración de los objetos y los signos adquiere sus connotaciones más interesantes desde el punto de vista de una filosofía materialista de la historia, aparece sobre todo durante el siglo XIX.

Es bajo el despliegue del capitalismo industrial donde se aprecia con cierta nitidez la profundidad de la transfiguración que el acto de coleccionar lleva a cabo: al incorporar los objetos a su colección, en realidad, el coleccionista acomete la "tarea de Sísifo de poseer las cosas para quitarles su carácter de mercancía. Pero él no podría conferirles sino el valor que ellas tienen para el aficionado, en lugar del valor de uso" (Benjamin, 2005, p. 55). Mediante esta transfiguración de las piezas de su colección, el coleccionista no solo arranca las cosas de un contexto para que irrumpan en otro, sino que además las libera de la servidumbre de ser útiles, dotándolas más bien de una valor fundamentalmente afectivo. Así, podría afirmarse que la relación del coleccionista con las cosas destruye el registro de la mercancía que está en las entrañas del capitalismo. Por lo tanto, a nivel micro, en su manera de habitar el interior burgués, el coleccionista moderno crea todo un mundo que, a diferencia de los universos de las Wunderkammer renacentistas, encuentra su radicalidad en la interrupción de la circulación mercantil.

El valor de los signos o los objetos que el coleccionista arrebata del mercado ya no puede reducirse ni al valor de cambio ni al valor de uso que estos tenían en el régimen de circulación de las mercancías. Esto significa que, según la filosofía benjaminiana, dicha liberación de la cosas de su esclavitud de ser útiles es realizada por el coleccionista en virtud de una peculiar autenticidad que pasan a obtener dentro de su colección. Al mismo tiempo, como bien lo dice Giorgio Agamben (2005, p. 169), tal autenticidad implica el extrañamiento "a través del cual ha tenido lugar esa liberación y la sustitución del valor de uso por el valor afectivo. En otras palabras, la autenticidad del objeto mide su valor-extrañamiento, y éste, a su vez, es el único espacio en el que se sostiene la idea de colección". El carácter irreductible de ese valor afectivo de las cosas, por medio del cual el coleccionista las reinscribe en su colección, otorga buena parte del potencial de su figura para una filosofía materialista de la historia, que es en definitiva hacia donde Benjamin conducirá su reflexión sobre el coleccionismo.

\section{ANARChiVismo y MATERIALISMo histórico.}

Se ha dicho con razón que, en el pensamiento benjaminiano, el coleccionista es "siempre un coleccionista de imágenes dialécticas" (Gourouris, 2006, p. 221). La noción de imagen dialéctica es clave en el anarchivo del Libro de los pasajes. Allí, en el legajo sobre Teoría del conocimiento, dicha noción se define como "aquello en donde lo que ha sido se une como un relámpago al ahora en una constelación" (Benjamin, 2005, p. 465). Puesto en otros términos, la imagen dialéctica suspende el orden temporal, la 
línea cronológica del tiempo. Estas imágenes no son proyectadas en el presente para iluminar el pasado, ni dan luces al presente desde el pasado, más bien cifran el instante de cognoscibilidad del "tiempo ahora" como escisión de la propia temporalidad. La imagen dialéctica no es una superación de una temporalidad por otra, sino la coexistencia de ellas en una misma tensión, la prehistoria e historia de una huella tensionadas en la misma imagen. Este asunto ocupa un lugar central en los apuntes sobre la teoría del conocimiento de Benjamin y en la arquitectura epistemológica del proyecto del Passagen-Werk. Consecuentemente, el anarchivo de citas del Libro de los pasajes sugiere un vínculo especial entre la práctica del coleccionista y la efracción de la linealidad del tiempo.

Clave para profundizar en esta conexión es el ensayo que Benjamin publica sobre Eduard Fuchs en 1937. No es casual que en ese texto Benjamin emparente de algún modo la labor del coleccionista con la del historiador, ya que ciertamente la práctica del coleccionista no deja de remitir a una singular operación histórica. Allí se sostiene que Fuchs no fue sólo un pionero en la consideración materialista de la cultura, sino que además lo que "hizo de este materialista un coleccionista radical fue la idea más o menos clara del estadio histórico en que se veía insertado, es decir, de la situación del materialismo histórico en sí mismo" (Benjamin, 2009, p. 69). De este modo, podría decirse que la figura benjaminiana del coleccionista supone siempre una afección histórica que la hace alterar toda temporalidad cosificada de la historia. Así como es capaz de liberar objetos e inscripciones de la circulación mercantil, la práctica del coleccionista podría escapar al ordenamiento histórico dispuesto principalmente por el archivo y su administración de la herencia cultural. Desde la perspectiva de Benjamin, el coleccionista actúa como materialista histórico en tanto su relación con los archivos de la historia no puede ser aproblemática, y esto porque: "No existe un documento de la cultura que no lo sea a la vez de la barbarie" (Benjamin, 1995, p. 52). Si los archivos de la cultura han sido dispuestos por los vencedores de la historia, el anarchivismo del coleccionista benjaminiano no puede sino interrumpir el relato histórico que desde allí se legítima. De esta manera, al referirse al procedimiento de montaje del anarchivo del Libro de los Pasajes, Benjamin declara: "No hurtaré nada valioso, ni me apropiaré de ninguna formulación profunda. Pero los harapos, los desechos, esos no los quiero inventariar, sino dejarles alcanzar su derecho de la única manera posible: empleándolos" (Benjamin, 2005, p. 462).

En ese sentido, la práctica del coleccionista como anarchivista coincide con la figura del chiffonier [trapero], poetizada por Baudelaire ${ }^{3}$. El chiffonier recolecta aquello que es rechazado a diario en la capital, lo que la gran ciudad desecha. Escarbando en la basura, entre lo defenestrado rápidamente por el avance modernizador de la cultura del capitalismo, el trapero rescata las cosas con el afán del coleccionista. Acertadamente, Susan Buck-Morss (2005, p. 22) pone de relieve la similitud de esta práctica con la del propio Benjamin hurgando el archivo, "revolviendo estantes en viejas librerías, pujando en subastas por volúmenes que nadie quería, desenterrando polvorientos tomos en la Bibliothèque Nationale, despertándolos de la muerte". Al igual que el anarchivismo del coleccionista, y replicando en cierto modo el gesto del trapero, Benjamin prefiere dejar de lado los grandes libros de la tradición intelectual, las obras consagradas del archivo, atendiendo en cambio a los textos e inscripciones descuidadas.

Desde esta práctica anarchivista puede entenderse también el aporte de Fuchs como coleccionista de caricaturas, arte erótico y cuadros de costumbres. Ese tipo de colecciones se conforma a partir de inscripciones desechadas por las instituciones culturales de la época, o mejor dicho, por los criterios de clasificación y valoración del archivo. Por ese motivo, al igual que todo coleccionista que es al mismo tiempo un materialista histórico, Fuchs siente aversión por los museos, pues su pasión se orienta más bien hacía lo abandonado, dirige "la mirada a las cosas desapreciadas y apócrifas" (Benjamin 2009, p. 108). Asimismo, el materialismo histórico de Benjamin plantea un gesto de recolección de las huellas que no han tenido cabida en los salones de la alta cultura, rescatándolas de las letrinas del archivo. Un montaje con los desechos del archivo es el método que adopta para peinar a contrapelo la historia.

El ensayo sobre Fuchs constituye también un importante complemento para 
entender una de las tesis que Benjamin había expuesto antes en Ich packe meine Bibliothek aus, su breve discurso sobre el coleccionismo de 1931. Allí, Benjamin afirma que el coleccionista mantiene siempre "una enigmática relación con la propiedad", puesto que a las cosas "las estudia y las aprecia como escenario donde se juega su destino" (Benjamin, 2010c, p. 338). Lejos de hacer una suerte de apología de la propiedad privada, Benjamin abre de este modo una sigilosa reflexión sobre la particularidad de las posesiones del coleccionista, que puede llegar a desafiar las ideas de la izquierda biempensante, y que sin embargo, resulta crucial para su singular filosofía materialista de la historia. Hay que reconocer que "el fenómeno del coleccionismo pierde su significado si se pierde la propiedad personal" (Ibid., p. 344). ¿Cómo entonces aceptar este aferramiento del coleccionista con sus posesiones desde la óptica del materialismo histórico? Pues bien, lo cierto es que esto "sólo se logra repensando la naturaleza de la posesión" (Abbas, 2005, p. 223). En efecto, para entender esta irrenunciable posesión de las cosas que caracteriza al coleccionismo según las tesis de Benjamin, hay que subrayar que para el coleccionista "la propiedad es la más honda relación que puede establecerse con las cosas: y no porque la cosas estén vivas en él, sino que es él quien habita en ellas" (Benjamin, 2010c, p. 345). Reaparece aquí, una vez mas, el valor afectivo de las cosas que da vida al coleccionista. De esta manera, el coleccionista parece transformar la experiencia de la posesión en una posesión de experiencias. Y lo hace, justamente, con objetos que arranca de la circulación mercantil y, con ello, los erradica también de la celebración del culto capitalista.

Pero si la relación afectiva con sus posesiones es la que permite al coleccionista liberarlas de cualquier utilidad mercantil, dicha experiencia, como lo describimos al comienzo de este artículo, va de la mano con la evocación del recuerdo que las piezas de la colección generan en su propietario. En ese sentido, podría afirmarse que reaparece nuevamente la "convergencia del coleccionista y el historiador", pues esta "envuelve la convergencia de un pensamiento alegórico y un elaborado conocimiento del significado histórico", cuya significación más profunda es que "el coleccionista se convierte en la clave de una economía omitida en la clasificaciones de Marx de valor de uso y valor de cambio: la economía material de la memoria o el valor mnemónico» (Steinberg, 1996, p. 115). Precisamente, es la singularidad mnémica con que el coleccionista se relaciona con sus posesiones la que distingue, al mismo tiempo, su relación con la historia y lo convierte en un materialista histórico. Benjamin aclara esto aún más en su ensayo sobre Fuchs, donde sostiene que el coleccionista: "tiene en su pasión una varita mágica para descubrir nuevas fuentes” (Benjamin, 2009, p. 105). Por lo tanto, la relación del coleccionista con sus posesiones no sólo destaca por sacar fuera de circulación las cosas y los signos, sino que resalta además por tomar estas cosas que están fuera de circulación y confrontar con ellas la representaciones del pasado o las configuraciones de la historia. En otras palabras, el coleccionista amenaza sin cesar el ordenamiento del archivo.

Este anarchivismo ha sido muy bien descrito en la observación de Arendt (1990, p. 185) sobre la figura benjaminiana del coleccionista: "el heredero y conservador se convierte en forma inesperada en destructor". La figura del coleccionista manifiesta así un sentido de la propiedad tan excepcional que puede vincularse con la del "materialista histórico" concebido por Benjamin. Para este último el concepto de "cultura" es tan problemático como su descomposición en bienes para la preservación, pues: "la obra del pasado no está nunca cerrada. El materialismo histórico no ve caer a la obra del pasado como una cosa en manos de una época, ni en ninguna parte en todo caso" (Benjamin, 2009, p. 80). Así, la práctica del coleccionista benjaminiano atenta necesariamente contra la reificación de los documentos, los objetos, los signos y las obras que resguardan los archivos de nuestra cultura. Y con ello, desafía las formas unilaterales con que comprendemos y percibimos el mundo. 


\section{BibLiOgRAFÍA}

ABBAS, Akbar. Walter Benjamin's collector: the fate of modern experience. En: OSBORNE, Peter (ed.). Walter Benjamin. Critical evaluations in cultural theory. Vol. II, Modernity. London: Routledge, 2005.

ADORNO, Theodor. Sobre Walter Benjamin. Madrid: Cátedra, 1995.

AGAMBEN, Giorgio. El hombre sin contenido. Barcelona: Áltera, 2005.

ALLEN, Jennifer. Préface. En: BENJAMIN, Walter. Je déballe ma bibliothèque. Une pratique de la collection. París: Payot \& Rivage, 2000.

ARENDT, Hannah. Hombres en tiempos de oscuridad. Barcelona: Gedisa, 1990.

BENJAMIN, Walter. La dialéctica en suspenso. Fragmentos sobre la historia. Santiago de Chile: Arcis-Lom, 1995.

BENJAMIN, Walter. Libro de los Pasajes. Madrid: Akal, 2005.

BENJAMIN, Walter. Hacia una imagen de Proust. En: BENJAMIN, Walter, Obras. Libro II/ vol.1. Madrid: Abada, 2007a.

BENJAMIN, Walter. Karl Kraus. En: BENJAMIN, Walter Obras. Libro II/ vol 1. Madrid: Abada, 2007b.

BENJAMIN, Walter. Parque Central. En: BENJAMIN, Walter Obras libro I/ vol. 2. Madrid: Abada, 2008.

BENJAMIN, Walter. Eduard Fuchs, coleccionista e historiador. En: BENJAMIN, Walter Obras libro II/ vol. 2. Madrid: Abada, 2009.

BENJAMIN, Walter. Calle de dirección única. En: BENJAMIN, Walter. Obras libro IV/ vol. 1. Madrid: Abada, 2010a.

BENJAMIN, Walter. Desenterrar y recordar. En: BENJAMIN, Walter. Obras libro IV/ vol. 1. Madrid: Abada, 2010b.

BENJAMIN, Walter. Voy a desembalar mi biblioteca. Un discurso sobre el coleccionismo. En: BENJAMIN, Walter. Obras. Libro IV/ vol. I. Madrid: Abada, 2010c.

BENJAMIN, Walter. Imágenes que piensan. En: BENJAMIN, Walter. Obras. Libro IV/ vol. I. Madrid: Abada, 2010d.

BUCK-MORSS, Susan. Dialéctica de la mirada. Walter Benjamin y el proyecto de los Pasajes. Madrid: Visor, 1995.

BUCK-MORSS, Susan. Walter Benjamin, escritor revolucionario. Buenos aires: Interzona, 2005.

DERRIDA, Jacques. El libro por venir. En: DERRIDA, Jacques. Papel Máquina. La cinta de máquina de escribir y otras respuestas. Madrid: Trotta, 2003.

GOUROURIS, Statis. The dream-reality of the ruin. En: HANSSEN, Beatrice (ed.) Walter Benjamin and the Arcades Project. London: Continuum, 2006.

HERNÁNDEZ, Domingo. La idea de Europa en la estética del archivo. En: HERNÁNDEZ, Domingo. La ironía estética. Estética romántica y arte moderno. Salamanca: Ediciones de la Universidad de Salamanca, 2002.

HERRERO, Ana; DÍAZ, Alfonso. La clasificación. En: CRUZ MUNDET, José Ramón (dir.). Administración de documentos y archivos. Textos fundamentales. Madrid: CAA, 2011.

KÖHN, Eckhardt. Coleccionista. En: OPITZ, Michael; WIZISLA, Ermudt (eds.). Conceptos de Walter Benjamin. Buenos Aires: Las cuarenta, 2014.

LESLIE, Esther. Walter Benjamin. London: Reaktion Books, 2007.

LEWANDOWSKI, Joseph. Unpacking Benjamin and his library. En: Libraries \& Culture 34, no. 2, Spring, 1999.

LUGLI, Adalgisa. Naturalia et mirabilia. Il collezionismo enciclopedico nelle Wunderkammern d'Europa. Milano: Gabriele Mazzotta, 1983.

MARX, Ursula. Árbol del esmero. Benjamin como archivero. En: WALTER BENJAMIN ARCHIV (ed). Archivos de Walter Benjamin: Fotografias, textos y dibujos. Madrid: Círculo de Bellas Artes, 2010. 
MISAAC, Pierre. Walter Benjamin: De un siglo al otro. Barcelona: Gedisa, 1997.

POSNER, Ernst. Max Lehmann y el origen del principio de procedencia. En: WALNE, Peter (comp.). La Administración Moderna de Archivos y la Gestión de Documentos. París: UNESCO, 1985.

RENDUELES, César; USEROS Ana. Atlas Walter Benjamin Constelaciones. Madrid: Circulo de Bellas Artes, 2010.

SCHOLZ, Leander. La noche del coleccionista. En: Elementos 9, no. 48, Febrero 2003.

STEINBERG, Michael. The collector as allegorist: Goods, gods, and the objects of History, En: STEINBERG, Michael (ed.). Walter Benjamin and the demands of History. Nueva York: Cornell University Press, 1996.

TACKELS, Bruno. Walter Benjamin: Una vida en los textos. Valencia: Universidad de Valencia, 2012.

WIZISLA, Erdmut. Prólogo. En: WALTER BENJAMIN ARCHIV (ed). Archivos de Walter Benjamin: Fotografías, textos y dibujos. Madrid: Círculo de Bellas Artes, 2010a.

WIZISLA, Erdmut. Escritura dispersa. Reunión y dispersión. En: WALTER BENJAMIN ARCHIV (ed). Archivos de Walter Benjamin: Fotografias, textos y dibujos. Madrid: Círculo de Bellas Artes, 2010b.

\section{Notas}

1 Para más detalles sobre la elaboración de los konvoluts, véase: Susan Buck-Morss, Dialéctica de la mirada. Walter Benjamin y el proyecto de los Pasajes (Madrid: Visor, 1995), 68-9.

2 Rudimento fundamental de la ratio archivística que es implementado con las «Instrucciones» dadas en 1841 por el Ministerio del Interior francés bajo la influencia del historiador y archivador Natalis de Wailly, para reemplazar los criterios de clasificación de documentos utilizados desde la Ilustración y centrados principalmente en la división por «materias», «temas» o «lugares». Denominado en francés respect des fonds, el «principio de procedencia» instituye la práctica de «unir los diferentes documentos por fondos, es decir reunir todos los títulos que provengan de un "cuerpo", de un "establecimiento", de una familia o de un individuo, y colocar después con un cierto orden los diferentes fondos». Y ello, sin que los documentos ligados únicamente a un fondo sean confundidos con el fondo mismo. Dicho de otro modo, el «principio de procedencia» es un procedimiento sistemático de identificación, ordenamiento y conservación de los documentos a partir de su cuerpo o institución de origen. Paradigmáticamente, la procedencia determina entonces el orden de las inscripciones en el archivo. La expansión e implementación en Prusia del «principio de procedencia» resulta igualmente paradigmática. Ocurre el año 1881 con la publicación del Regulative für die Ordnungsarbeiten in Preussischen Geheimen Staatsarchiv [Reglamento para la ordenación de los Archivos Secretos Estatales de Prusia] por Heinrich von Sybel, director de los Archivos del Estado Prusiano. Mediante este texto se decreta la división y reclasificación de los documentos dentro de los Archivos Estatales de acuerdo al origen de sus unidades administrativas originales, pero además, su particularidad radicaría en que el establecimiento del principio de procedencia [Provenienzprinzip] se articula aquí con la formulación de un principio de respeto del orden original [Registraturprinzip]. Sobre esto véase: Ana Herrero y Alfonso Díaz, "La clasificación", en José Ramón Cruz Mundet (dir.), Administración de documentos y archivos. Textos fundamentales (Madrid: CAA, 2011). Y también: Ernst Posner, "Max Lehmann y el origen del principio de procedencia," en La Administración Moderna de Archivos y la Gestión de Documentos, comp. Peter Walne (París: UNESCO, 1985).

3 Se ha subrayado con razón que una figura central en la metodología de Benjamin "es la del coleccionista: no el esteta exquisito a la búsqueda de lo sublime, sino el trapero, el chiffonnier -un motivo que alude a un conocido poema de Baudelaire en Las flores del mal-, el espigador de la cultura que rastrea sus deshechos". Véase: César Rendueles y Ana Useros, Atlas Walter Benjamin Constelaciones (Madrid: Circulo de Bellas Artes, 2010), 19. 